\title{
Enhanced Bone Regeneration in Beagle Dogs With Bovine Bone Mineral Coated With a Synthetic Oligopeptide
}

Jun-Beom Park, * Jue-Yeon Lee, ${ }^{\dagger}$ Yoon-Jeong Park, $\S_{\S}$ Sang-Hoon Rhee, $§ \|$ Sang-Cheol Lee, ${ }^{\dagger}$ Tae-Il Kim, * Yang-Jo Seol, * Yong-Moo Lee, * Young Ku, *§ In-Chul Rhyu, * Soo-Boo Han, * and Chong-Pyoung Chung*§

Background: Recombinant human bone morphogenic protein-2 stimulates bone augmentation in animal models. The aim of this study was to evaluate the capacity of bovine bone mineral coated with synthetic oligopeptides to enhance guided bone regeneration in the beagle 3 -wall defect model and the clinical implications.

Methods: The second and fourth mandibular premolars of four adult beagle dogs were extracted bilaterally, and the extraction sites were allowed to heal for 2 months. An L-shaped defect was prepared at the central part of the extraction site with a round bur on a low-speed motor. Peptide-coated bone mineral was implanted on one side, and uncoated bone mineral was implanted on the other side. The membrane was tucked underneath the mobilized lingual flap. New bone formation at the test and control sites was determined at 4 weeks.

Results: No specimen revealed any evidence of infection or foreign body reaction, and all wounds showed a good healing response. Sites augmented with peptide-coated bone mineral and uncoated mineral exhibited excellent maintenance of the ridge contour. There was more new bone at sites with peptidecoated bone mineral than at control sites. The new bone in sites with peptide-coated bone mineral was deposited evenly around the graft material, and bone mineral was integrated fully into the new bone.

Conclusion: Deproteinized cancellous bovine bone coated with synthetic oligopeptides enhanced new bone formation, and it seemed to be a better material for guided bone regeneration in the beagle L-shaped defect model. J Periodontol 2007; 78:2150-2155.

\section{KEY WORDS}

Animal studies; bone regeneration; oligopeptide.

* Department of Periodontology, School of Dentistry, Seoul National University, Seoul, Korea.

$\dagger$ Nano-Intelligent Bioengineering Corp., Seoul, Korea.

† Department of Craniomaxillofacial Reconstructive Sciences, School of Dentistry, Seoul National University.

$\S$ Intellectual Biointerface Engineering Center, Korea Science and Engineering Foundation, Seoul, Korea.

|| Department of Dental Biomaterials Science, School of Dentistry, Seoul National University.
$\mathrm{V}$ arious graft materials, including allografts, xenografts, and alloplastic materials, are used for guided bone regeneration because of limited autogenous bone availability. Hard tissue graft material is combined often with bioabsorbable or non-resorbable membranes. The membranes prevent epithelial cell migration and protect the graft material. ${ }^{1}$ Despite these attempts, new bone formation is limited, and there are impediments in the implant procedures. Therefore, early bone formation is necessary. Recombinant human bone morphogenetic protein-2 (rhBMP-2) stimulated bone augmentation in an animal model. ${ }^{2,3}$ Bone morphogenetic protein (BMP)-2 and other growth factors are difficult to use because of their high molecular weights, immunological responses, cost, coupling to scaffolds, and problems in targeting to remote organs. Synthetic peptides have been suggested to overcome these shortcomings. ${ }^{4-6}$

In this study, deproteinized bovine bone granules coated with 15 amino acid oligopeptides corresponding to BMP receptor I (BMPRI) and BMP receptor II (BMPRII) binding domains were used. The cells grown with peptide-loaded bone mineral had significantly higher proliferation than cells grown with unloaded bone mineral in the rabbit calvarial defect. ${ }^{7}$ A synthetic BMP-2 receptor binding motif was linked covalently to titanium surfaces through a 

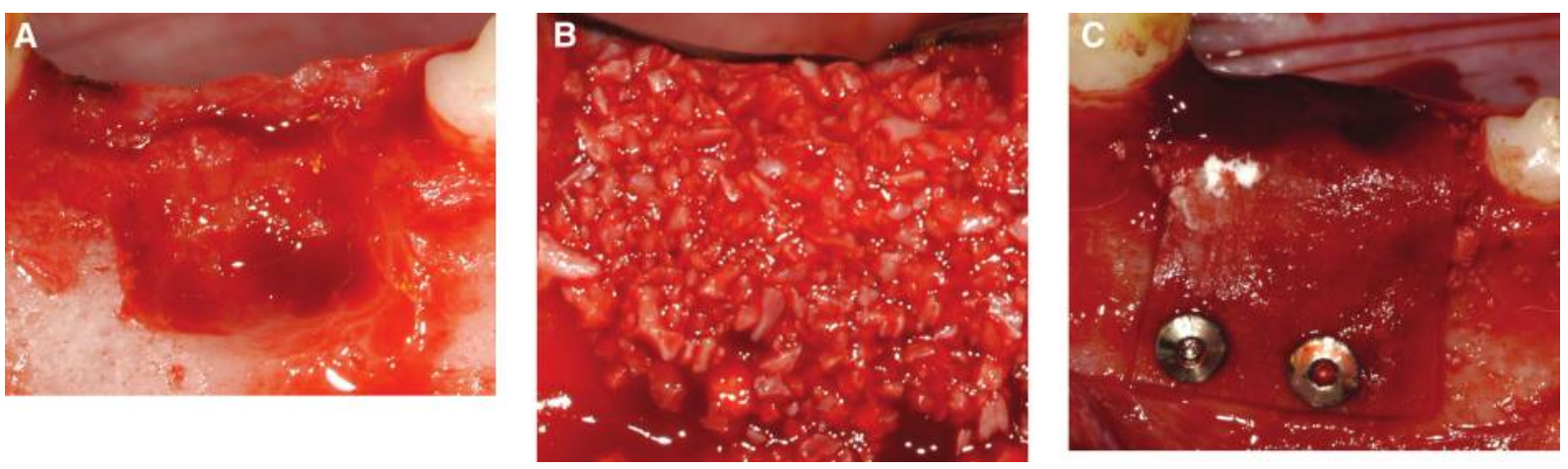

Figure 1 .

A) An 8 (mesio-distal) $\times 6$ (apico-coronal) $\times 5 \mathrm{~mm}$ (bucco-lingual) bone defect was prepared at the central part of the extraction area. B) The defects were augmented randomly with uncoated bone mineral on one side and peptide-coated bone mineral on the other side (uncoated bone mineral is shown here). C) The membrane was applied to the defect and stabilized with two membrane fixation pins.

chemical conjugation process, resulting in a significant increase in bone growth. The investigators suggested that modifying titanium surfaces biochemically could enhance bone healing compared to untreated titanium. ${ }^{4}$

The aim of this study was to evaluate the ability of bovine bone mineral coated with synthetic oligopeptides to enhance guided bone regeneration in the beagle L-shaped defect model and the possible clinical implications.

\section{MATERIALS AND METHODS}

\section{Preparing Peptide-Coated Deproteinized Bovine Bone}

Deproteinized cancellous bovine bone particles and peptide-coated bone mineral ${ }^{\text {Il }}$ were created by the method reported previously. ${ }^{7}$

A peptide sequence corresponding to the cell-binding domains of BMPRI and BMPRII, containing sequence DWIVA, was obtained from the manufacturer." The peptide was synthesized chemically using an automatic peptide synthesizer** by the manufacturer." The peptide was modified further at its $\mathrm{N}$-terminal with a spacer to facilitate the coating of the bone material with the peptide.

Deproteinized cancellous bovine bone particulates between 0.2 and $1.00 \mathrm{~mm}$ in size were used. The peptide was applied by incubating the bone for 24 hours in a solution containing the peptide in phosphate buffered saline (PBS). The incubation was carried out at room temperature with gentle shaking to ensure equilibration of the peptide with all exposed surfaces of the microporous bovine bone. Following incubation, the bone mineral was washed three times by shaking with a $5 \times$ volume of PBS over a 24 -hour period to remove unadsorbed peptide. The bone mineral was collected, dried, and then sterilized by gamma irradiation.

\section{Surgical Procedure}

Creation of artificial bony defects and ridge augmentation surgery. Four adult male beagle dogs, weighing $\sim 15 \mathrm{~kg}$ each, were used as study subjects. The animal protocol was approved by the Institute of Laboratory Animal Resources, Seoul National University. A randomized, double-masked split-mouth design was applied in this study. The animals had intact dentition with a healthy periodontium. Equal amounts of $2 \%$ xylazine hydrochloride ${ }^{\dagger \dagger}$ and ketamine hydrochloride ${ }^{\ddagger}$ were used for general anesthesia; $2 \%$ lidocaine with epinephrine $(1: 100,000)$ was used for local anesthesia. Under anesthesia, the second and fourth mandibular premolars were extracted bilaterally. The extraction sites were allowed to heal for 2 months.

During the experimental surgery, the periodontal flap was elevated, and an L-shaped defect ${ }^{8}$ measuring 8 (mesio-distal) $\times 6$ (apico-coronal) $\times 5 \mathrm{~mm}$ (buccolingual) was prepared at the central part of the extraction site with a round bur on a low-speed motor (Fig. 1A). Copious sterile saline irrigation was used during preparation of the bone defects. Although individual differences in the alveolar ridge dimensions did not allow a perfect standardization of the defects, a careful effort was made to keep the defect dimensions reasonably constant in size.

Peptide-coated bone mineral was implanted on one side, and uncoated bone mineral was implanted on the other side (Fig. 1B). The membrane $\$ \S$ was trimmed to overlap the defect margins by $\sim 2 \mathrm{~mm}$ and tucked underneath the mobilized lingual flap.

II OssGen X-15, Nano-Intelligent Bioengineering Corp. (NIBEC), Seoul, Korea.

\# NIBEC

** APEC 396, Advanced ChemTech, Louisville, KY.

$\dagger \dagger$ Rumpen, Bayer Korea, Seoul, Korea.

\# Ketalar, Yuhan, Seoul, Korea.

$\S \S$ Bio-Gide, Osteohealth, Wolhusen, Switzerland. 

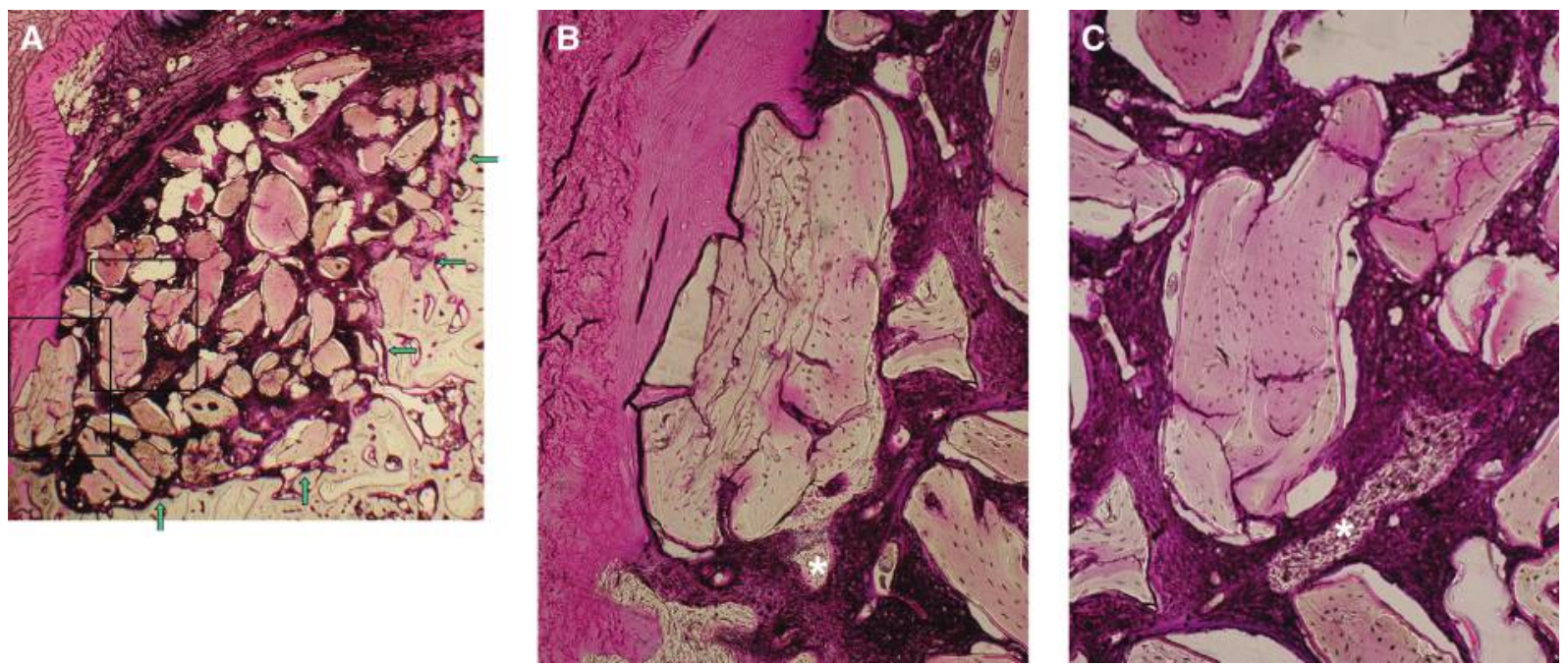

Figure 2.

A) Histologic view of a specimen with uncoated bone mineral at 4 weeks. The bony margin is indicated by the arrows. The width of the ridge is well maintained, but bone formation was limited. $\mathbf{B}$ and $\mathbf{C})$ Higher magnification of the boxes shown in $\mathrm{A}$. There was limited bone formation around the graft material. New bone formation was sparse (*). (Multiple staining; original magnification: $A, \times 20 ; B$ and $C, \times 100$.)

The membrane was stabilized with two membrane fixation pins $1 \|$ on the buccal aspects (Fig. 1C). The periosteum was released at its base, and the wound margins were reapproximated and closed with interrupted sutures for a tension-free closure. The average percentage of new bone formation at the test and control sites was determined at 4 weeks.

\section{Histologic Preparation and \\ Histomorphometric Evaluation}

The animals were sacrificed 4 weeks after surgery. The retrieved specimens were fixed in $10 \%$ neutral buffered formalin, dehydrated in an ethanol series, and embedded in embedding media. "TाI Two coronal sections close to the center of the defects were sliced, ground, ${ }^{\# \#}$ and stained (basic fuchsin and toluidine blue methods). Examination was conducted using a light microscope. ***

Photographs of each slide were taken using a digital camera, ${ }^{\dagger \dagger}$ and the images were saved on a computer. Computer-assisted histomorphometric measurements of the newly formed bone, graft particles, and soft tissue were obtained using an automated image analysis system. ${ }^{\neq \neq} \neq$The ratio of bone regeneration was calculated as the area of newly formed bone divided by the original defect area. ${ }^{9}$

\section{Statistical Analysis}

Statistical analysis was performed using software. $\S \S \S$ Data are reported as mean $\pm S D$ with a significance level of $P<0.05$. A paired Student $t$ test was performed to compare data from the in vivo histomorphometric analysis.

\section{RESULTS}

\section{Observation of Bone Regeneration in Artificial Bony Defect}

No specimen revealed any evidence of infection or foreign body reaction, and all wounds healed well. Excellent ridge contour maintenance was seen in both groups.

Although a few bony islands were found in the coronal part of the defect, the defect area was occupied primarily by the graft material and the connective tissue at the sites that had uncoated bone mineral (Fig. 2A). The new bone formation was minimal (Figs. 2B and $2 \mathrm{C}$ ), and the newly formed bone was located mainly near the defect border.

In the sites with peptide-coated bone mineral, new bone formation was observed throughout the defect (Fig. 3A). The quantity of new bone at sites with peptide-coated bone mineral was greater than at control sites. Most of the specimens showed new bone formation extending to the coronal part of the defect. The new bone was deposited evenly around the graft material, the bone mineral was integrated fully with the new bone, and newly formed bone exhibited a trabecular pattern (Figs. 3B and 3C). The appearance of new bone in the group with peptide-coated bone mineral was more mature than in the group with uncoated bone mineral.

||| Frios pin, Riatec, Mannheim, Germany.

II Technovit 7200, Exakt, Hamburg, Germany.

\#\# Exakt.

*** Olympus BH-2, Olympus Optical, Osaka, Japan.

$\dagger \dagger \dagger$ Olympus Optical.

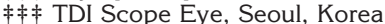

$\S \S \S$ SPSS v. 10.1, SPSS/PC, Chicago, IL. 

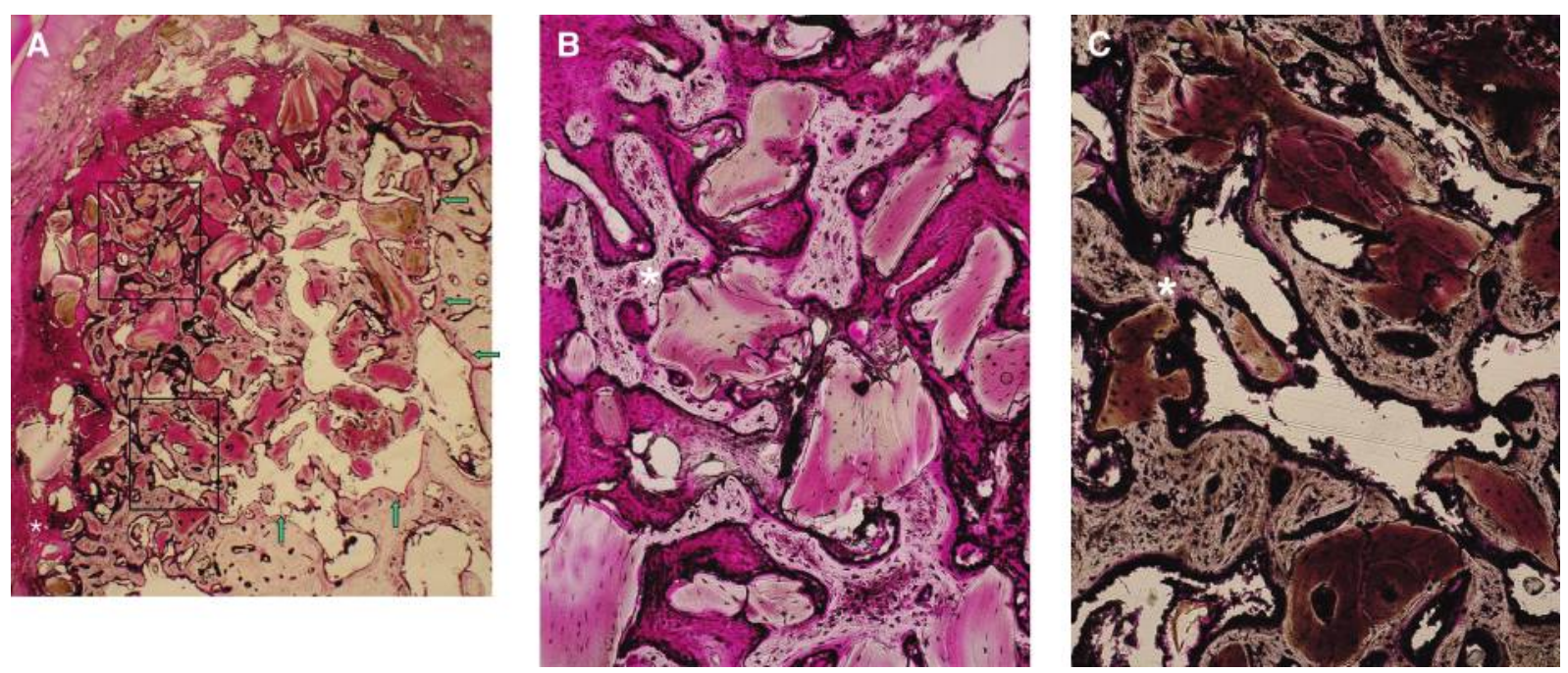

Figure 3.

A) Histologic view of a specimen with peptide-coated bone mineral at 4 weeks. New bone formation was noted across the defect area and was more pronounced than with using uncoated bone mineral. The bony margin is indicated by the arrows. $\mathbf{B}$ and $\mathbf{C}$ ) Higher magnification of the boxes shown in $\mathrm{A}$. New bone that formed around the particles was integrated well with the bone mineral (*). (Multiple staining; original magnification: A, $\times 20 ; B$ and C, $\times 100$.)

\section{Histomorphometric Evaluation}

The results of the histomorphometric analysis are shown in Table 1 . The average area occupied by new bone was $5.7 \% \pm 3.8 \%$ for the sites with uncoated bone mineral and $25.6 \% \pm 6.1 \%$ for the sites with peptide-coated bone mineral. The proportions of soft tissue were $62.2 \% \pm 8.9 \%$ for the control sites and $47.6 \% \pm 3.8 \%$ for the test sites. There were significant differences in the regenerated area and the soft tissue area between the two groups $(P<0.05)$. The average proportion of the sample occupied by deproteinized bovine bone particle was not significantly different between the two groups $(P>0.05)$.

\section{DISCUSSION}

Defects can be categorized as submerged or non-submerged. ${ }^{10}$ Submerged defects have the periodontal defect, root, and crown under mucoperiosteal flaps. ${ }^{11}$ Non-submerged defects use a flap over a periodontal bony defect around a tooth or teeth. ${ }^{12}$

\section{Table I.}

\section{Induced Bone Formation (mean $\pm \mathrm{SD}$ )}

\begin{tabular}{lccc}
\hline Group & $\begin{array}{c}\text { Regenerated } \\
\text { Bone (\%) }\end{array}$ & $\begin{array}{c}\text { Graft } \\
\text { Particles (\%) }\end{array}$ & $\begin{array}{c}\text { Soft } \\
\text { Tissue (\%) }\end{array}$ \\
\hline $\begin{array}{c}\text { Uncoated bone } \\
\text { mineral }\end{array}$ & $5.7 \pm 3.8$ & $32.2 \pm 9.5$ & $62.2 \pm 8.9$ \\
$\begin{array}{c}\text { Peptide-coated } \\
\text { bone mineral }\end{array}$ & $25.6 \pm 6.1^{*}$ & $27.0 \pm 4.8$ & $47.6 \pm 3.8^{*}$ \\
\hline
\end{tabular}

* Significant difference between the two groups after 4 weeks $(P<0.05)$.
Defects also can be categorized as acute or chronic. In acute defects, some level of spontaneous regeneration is expected. ${ }^{13}$ In this study, a 2 -month healing period was used to minimize the effects of the extraction. The defects were created, and the augmentation procedures were done at the same time. The acute model has some research advantages, including a short time required to keep the animals and less difficulty in standardizing the defects.

Several types of defects have been used to evaluate new bone formation. Seibert and Nyman ${ }^{14}$ created bucco-lingual ridge defects averaging $13 \mathrm{~mm}$ mesiodistally, 7 to $8 \mathrm{~mm}$ coronally apically, and $3.5 \mathrm{~mm}$ bucco-lingually in the mandibular second and third premolar area. Kim et al. ${ }^{15}$ prepared box-type 1-, 2-, and 3-wall intrabony defects $(4 \times 4 \times 4 \mathrm{~mm})$ on the distal aspect of the mandibular second premolar and the mesial aspect of the mandibular second and fourth premolars. In this study, two standardized L-shaped defects were created on each side of the mandible. The anatomy of the bone defect (L-shaped) was expected to provide better support for the flaps and better stability for coagulum than through-and-through defect. ${ }^{16}$

rhBMP-2 seems to influence endochondral and intramembranous bone formation. ${ }^{17}$ Zegzula et al. ${ }^{18}$ reported that a $20-\mathrm{mm}$-long rabbit radius defect treated with 35 or $70 \mu \mathrm{g}$ rhBMP-2 and porous poly (DLlactic acid) was repaired completely after 8 weeks. Kaito et al. ${ }^{19}$ reported that a $15-\mathrm{mm}$-long rabbit radius defect treated with 5 and $20 \mu \mathrm{g}$ rhBMP- 2 was repaired completely, retaining sufficient strength after 8 weeks.

The optimum release pattern, BMP dosage, and BMP carrier have not been established. An excess 
BMP dosage may be dangerous because BMPs have many effects. ${ }^{20}$ Many reports show that BMPimpregnated polymers release most BMP with an initial high burst effect. Soon thereafter, local BMP concentrations dropped below the therapeutic level and lost their biologic activity as a result of degradation. ${ }^{21-23}$ This unwanted property, particularly with regard to the effectiveness of highly concentrated substances, has led to interest in receptor technology, which has proven to be a practical and cost-efficient method of accelerating bone regeneration. ${ }^{24}$

Saito et al. ${ }^{25}$ reported that alpha-tricalcium phosphate scaffolds impregnated with $5 \mathrm{mg}$ of a 73-92 peptide almost completely repaired 20 -mm-long rabbit radial bone defects after 12 weeks. The investigators suggested that 5 to $35 \mu \mathrm{g}$ rhBMP-2 would provide the same repair. Ectopic bone formation has been observed in alginated hydrogel linked to BMP-2 residues 68-87 when implanted into rat calf muscle. ${ }^{6}$ A 73-92 peptide also elevated alkaline phosphatase activity and osteocalcin mRNA in a murine cell line, and peptide-conjugated alginate gel prolonged ectopic calcification in rat calf muscle. ${ }^{26}$ Acceleration and denser bone regeneration was achieved when the 73-92 peptide-conjugated alginate gel particles were coimplanted with syngenic rat bone marrow stromal cells in a rat unicortical tibial defect. ${ }^{27}$ Enhanced bone healing was achieved when a BMP-2 peptide sequence was conjugated covalently to titanium surfaces. ${ }^{4}$

In this study, the peptide mentioned above was used to coat demineralized bovine bone, and the effects on bone regeneration were evaluated. The study was done at a 4-week period to evaluate bone formation in the early healing period. Histologic observations using multiple staining methods showed that no adverse response was induced by the graft, with or without peptide. The quantity of new bone at sites with peptide-coated bone mineral was greater than at sites with uncoated bone. The new bone was deposited evenly around the graft material, and the bone mineral was integrated fully with the new bone in test sites.

By histomorphometric analysis, the percentage gain in bone regeneration was calculated as the ratio of the area of newly formed bone to the area of the original defect, as reported previously. ${ }^{9}$ A significant finding in this study is the accelerated formation of new bone observed at test sites compared to control sites.

These results suggest that the formation of new bone and the normal healing process progress more rapidly when the synthetic oligopeptide is used.

\section{CONCLUSIONS}

The use of deproteinized cancellous bovine bone coated with a synthetic oligopeptide enhanced new bone formation. It seems to be a more beneficial material for clinicians because this can be translated into rapid formation of bone and, thus, shorter healing and faster recovery times after bone grafting and much faster completion of implants.

\section{ACKNOWLEDGMENTS}

This study was supported by the Korea Science and Engineering Foundation through the Intellectual Biointerface Engineering Center at Seoul National University. Jue-Yeon Lee and Sang-Cheol Lee are scientists at Nano-Intelligent Bioengineering Corp. None of the authors report any conflicts of interest related to this study.

\section{REFERENCES}

1. Buser D, Hoffmann B, Bernard JP, Lussi A, Mettler D, Schenk R. Evaluation of filling materials in membraneprotected bone defects. Clin Oral Implants Res 1998; 9:137-150.

2. Lee YM, Nam SH, Seol YJ, et al. Enhanced bone augmentation by controlled release of recombinant human bone morphogenetic protein-2 from bioabsorbable membranes. J Periodontol 2003;74:865-872.

3. Barboza EP, Duarte ME, Geolás L, Sorensen RG, Riedel GE, Wikesjö UM. Ridge augmentation following implantation of recombinant human bone morphogenetic protein-2 in the dog. J Periodontol 2000;71: 488-496.

4. Seol YJ, Park YJ, Lee SC, et al. Enhanced osteogenic promotion around dental implants with synthetic binding motif mimicking bone morphogenetic protein (BMP)-2. J Biomed Mater Res A 2006;77:599-607.

5. Sakiyama-Elbert SE, Hubbell JA. Functional biomaterials: Design of novel biomaterials. Annu Rev Mater Res 2001;31:183-201.

6. Suzuki Y, Tanihara M, Suzuki K, Saito A, Nishimura Y. Alginate hydrogel linked with synthetic oligopeptide derived from BMP-2 allows ectopic osteoinduction in vivo. J Biomed Mater Res 2000;50:405-409.

7. Park JB, Lee JY, Park HN, et al. Osteopromotion with synthetic oligopeptide-coated bovine bone mineral in vivo. J Periodontol 2007;78:157-163.

8. Zubery Y, Goldlust A, Alves A, Nir E. Ossification of a novel cross-linked porcine collagen barrier in guided bone regeneration in dogs. J Periodontol 2007;78: 112-121.

9. Shin SY, Park HN, Kim KH, et al. Biological evaluation of chitosan nanofiber membrane for guided bone regeneration. $J$ Periodontol 2005;76:1778-1784.

10. King GN, Cochran DL. Factors that modulate the effects of bone morphogenetic protein-induced periodontal regeneration: A critical review. $J$ Periodontol 2002;73:925-936.

11. Bowers G, Felton F, Middleton C, et al. Histologic comparison of regeneration in human intrabony defects when osteogenin is combined with demineralized freeze-dried bone allograft and with purified bovine collagen. J Periodontol 1991;62:690-702.

12. Kinoshita A, Oda S, Takahashi K, Yokota S, Ishikawa I. Periodontal regeneration by application of recombinant human bone morphogenetic protein-2 to horizontal 
circumferential defects created by experimental periodontitis in beagle dog. J Periodontol 1997;68:103-109.

13. von Arx T, Cochran DL, Hermann JS, Schenk RK, Buser D. Lateral ridge augmentation using different bone fillers and barrier membrane application. A histologic and histomorphometric pilot study in the canine mandible. Clin Oral Implants Res 2001;12:260-269.

14. Seibert J, Nyman S. Localized ridge augmentation in dogs: A pilot study using membranes and hydroxyapatite. J Periodontol 1990;61:157-165.

15. Kim CS, Choi SH, Chai JK, et al. Periodontal repair in surgically created intrabony defects in dogs: Influence of the number of bone walls on healing response. J Periodontol 2004;75:229-235.

16. Simion M, Dahlin C, Blair K, Schenk RK. Effect of different microstructures of ePTFE membranes on bone regeneration and soft tissue response: A histologic study in canine mandible. Clin Oral Implants Res 1999; 10:73-84.

17. Wozney JM, Rosen V, Celeste AJ, et al. Novel regulators of bone formation: Molecular clones and activities. Science 1988;242:1528-1534.

18. Zegzula HD, Buck DC, Brekke J, Wozney JM, Hollinger JO. Bone formation with use of rhBMP-2 (recombinant human bone morphogenetic protein-2). J Bone Joint Surq Am 1997;79:1778-1790.

19. Kaito T, Myoui A, Takaoka K, et al. Potentiation of the activity of bone morphogenetic protein-2 in bone regeneration by a PLA-PEG/hydroxyapatite composite. Biomaterials 2005;26:73-79.

20. Govender S, Csimma C, Genant HK, et al. Recombinant human bone morphogenetic protein-2 for treatment of open tibial fractures: A prospective, controlled, randomized study of four hundred and fifty patients. J Bone Joint Surg Am 2002;84-A:21232134.
21. Kenley RA, Yim K, Abrams J, et al. Biotechnology and bone graft substitutes. Pharm Res 1993;10:1393-1401.

22. Israel DI, Nove J, Kerns KM, Moutsatsos IK, Kaufman RJ. Expression and characterization of bone morphogenetic protein-2 in Chinese hamster ovary cells. Growth Factors 1992;7:139-150.

23. Hollinger JO, Mayer M, Buck D, et al. Poly( $\alpha$-hydroxy acid) carrier for delivering recombinant human bone morphogenetic protein-2 for bone regeneration. $\underline{J}$ Control Release 1996;39:287-304.

24. Tashiro K, Sephel GC, Weeks B, et al. A synthetic peptide containing the IKVAV sequence from the A chain of laminin mediates cell attachment, migration, and neurite outgrowth. J Biol Chem 1989;264:1617416182.

25. Saito A, Suzuki Y, Kitamura M, et al. Repair of 20-mm long rabbit radial bone defects using BMP-derived peptide combined with an $\alpha$-tricalcium phosphate scaffold. J Biomed Mater Res A 2006;77:700-706.

26. Saito A, Suzuki Y, Ogata S, Ohtsuki C, Tanihara M. Prolonged ectopic calcification induced by BMP-2derived synthetic peptide. J Biomed Mater Res A 2004; 70:115-121.

27. Saito A, Suzuki T, Ogata SI, Ohtsuki C, Tanihar M. Accelerated bone repair with the use of a synthetic BMP-2-derived peptide and bone-marrow stromal cells. J Biomed Mater Res A 2005;72:77-82.

Correspondence: Dr. Chong-Pyoung Chung, Department of Periodontology, School of Dentistry and Intellectual Biointerface Engineering Center, Seoul National University, 28-2 Yongon-Dong, Chongno-Gu, Seoul 110-749, Korea. Fax: 82-2-744-0051; e-mail: jbassoonis@yahoo.co.kr.

Submitted February 23, 2007; accepted for publication May 9, 2007. 